\title{
Prognostic utility of admission cell-free DNA levels in patients with chronic obstructive pulmonary disease exacerbations
}

This article was published in the following Dove Press journal:

International Journal of COPD

9 December 2016

Number of times this article has been viewed

\author{
Avital Avriel' \\ Dmitry Rozenberg ${ }^{2}$ \\ Yael Raviv' \\ Dov Heimer' \\ Amir Bar-Shai ${ }^{3}$ \\ Rachel Gavish ${ }^{4}$ \\ Jony Sheynin 5,6 \\ Amos Douvdevani ${ }^{6}$ \\ 'Department of Medicine, \\ Pulmonology Institute, Soroka \\ Medical Center, Ben-Gurion \\ University, Beer-Sheva, Israel; \\ ${ }^{2}$ Division of Respirology, \\ Department of Medicine, University \\ Health Network, University of \\ Toronto, Toronto, ON, Canada; \\ ${ }^{3}$ Department of Medicine, \\ Pulmonology Institute, Tel Aviv \\ Sourasky Medical Center, Tel \\ Aviv University, Tel Aviv, ${ }^{4}$ Faculty \\ of Health Sciences, Ben-Gurion \\ University, Beer-Sheva, Israel; \\ ${ }^{5}$ Department of Psychiatry, University \\ of Michigan, Ann Arbor, MI, USA; \\ ${ }^{6}$ Department of Clinical Biochemistry, \\ Faculty of Health Sciences, Soroka \\ Medical Center, Ben-Gurion \\ University, Beer-Sheva, Israel
}

Correspondence: Avital Avriel Department of Medicine, Pulmonology Institute, Soroka Medical Center, BenGurion University, Rager Boulevard, Beer-Sheva 84I0I, Israel

Tel+97286400287

Email avitalab@bgu.ac.il
Background: Chronic obstructive pulmonary disease exacerbations (COPDEs) are associated with increased morbidity and mortality. Cell-free DNA (cfDNA) is a novel biomarker associated with clinical outcomes in several disease states but has not been studied in COPD. The objectives of this study were to assess cfDNA levels during a COPDE, to evaluate the association of cfDNA with clinical parameters and to explore the prognostic implications of cfDNA levels on long-term survival.

Methods: This was an observational study that assessed cfDNA levels in patients admitted to hospital for a COPDE. Plasma cfDNA levels of COPDE patients were compared to those of matched stable COPD patients and healthy controls. Multivariable and Cox regression analyses were used to assess the association of cfDNA levels with blood gas parameters and long-term survival.

Results: A total of 62 patients (46 males, forced expiratory volume in 1 second [FEV $]_{1}$ $38 \% \pm 13 \%$ ) were included. The median cfDNA levels on admission for COPDE patients was $1,634 \mathrm{ng} / \mathrm{mL}$ (interquartile range [IQR] 1,016-2,319) compared to $781 \mathrm{ng} / \mathrm{mL}$ (IQR 523-855) for stable COPD patients, matched for age and disease severity, and $352 \mathrm{ng} / \mathrm{mL}$ (IQR 209-636) for healthy controls ( $P<0.0001$, for both comparisons). cfDNA was correlated with partial arterial pressure of carbon dioxide $\left(\mathrm{PaCO}_{2}, r=0.35\right)$ and $\mathrm{pH}(r=-0.35), P=0.01$ for both comparisons. In a multivariable analysis, $\mathrm{PaCO}_{2}$ was the only independent predictor of cfDNA. Using a cfDNA level of $1,924 \mathrm{ng} / \mathrm{mL}$ (threshold for abnormal $\mathrm{PaCO}_{2}$ ), those with high levels had a trend for increased 5-year mortality risk adjusted for age, sex and $\mathrm{FEV}_{1} \%$ (hazard ratio $1.92,95 \%$ confidence interval $0.93-3.95, P=0.08$ ).

Conclusion: Plasma cfDNA might offer a novel technique to identify COPD patients at increased risk of poor outcomes, but the prognostic utility of this measurement requires further study.

Keywords: chronic obstructive pulmonary disease, exacerbation, cell-free DNA, biomarker, prognosis

\section{Introduction}

COPDEs are defined by the GOLD guidelines ${ }^{1}$ as periods of symptom worsening that often lead to hospitalizations and respiratory failure. ${ }^{2}$ Exacerbations are associated with decreased quality of life, pulmonary function and increased mortality. ${ }^{3}$

Age and $\mathrm{PaCO}_{2}$ levels are two prognostic parameters that have been shown to be independently associated with mortality in COPDE. ${ }^{46}$ A novel approach, which incorporates specific blood biomarkers, can potentially help with the management of COPDE. However, to date there has been no accessible serological marker which has been applied in routine clinical practice..$^{7-10}$ 
Circulating cfDNA is a product of apoptotic cells and is actively released by immune cells during inflammation. cfDNA level increases proportionally with the rise in inflammation and cell damage. Thus, studying cfDNA during a COPDE is an important area of research given that exacerbations are marked by an increased inflammatory response $\mathrm{e}^{11,12}$ that is characterized by cell damage and apoptosis. ${ }^{11,13,14}$ Recently, cfDNA has been investigated as a reliable, novel prognostic marker in a number of disease states such as cancer, trauma, myocardial infarction and sepsis. ${ }^{15-24}$

We previously developed a novel, rapid and direct fluorescent assay for cfDNA quantification that has been shown to be inexpensive, accurate and reproducible, ${ }^{25}$ which we applied to a COPD cohort experiencing an exacerbation. The aims of this study were: 1) to assess cfDNA levels during a COPDE and compare to those of stable COPD patients and healthy controls, 2) to evaluate the association of cfDNA with known prognostic clinical and arterial blood gas markers during a COPDE and 3) to explore the prognostic implications of cfDNA levels on long-term survival. We hypothesized that levels of cfDNA would increase during a COPDE and reflect the severity of systemic inflammation characterized by cell damage, apoptosis and activation of immune cells. Given that these cellular processes potentially increase with COPD exacerbation severity, we believed that cfDNA levels would correlate with clinical measures such as $\mathrm{PaCO}_{2}$ and $\mathrm{pH}$ that characterize COPDE severity.

\section{Patients and methods Population}

This was a prospective, observational study in patients admitted from the ED to the internal medicine service with a COPDE at Soroka Medical Center, Israel, between January 1, 2009 and December 31, 2010 whose blood samples were collected to evaluate the cfDNA levels. All patients were older than 40 years and current or former smokers. We excluded patients with malignancy, renal replacement therapy, impaired level of consciousness, clinical and radiological evidence of pneumonia, sepsis, acute coronary syndrome, mechanical ventilation, treatment with vasopressors and those admitted to the ICU. We also excluded patients that did not satisfy the GOLD criteria for the diagnosis of COPD, as supported by spirometry that was performed in a stable state. ${ }^{26,27}$

Serum samples were drawn from 16 COPD outpatients (64 \pm 9 years, 10 females), who were seen consecutively in clinic at the Pulmonology Institute, Tel Aviv Sourasky
Medical Center, and met the GOLD criteria for COPD. ${ }^{1,26,27}$ Blood samples were obtained at a time when patients were in stable condition free of any respiratory exacerbations for more than 4 weeks. Serum samples were obtained from 10 healthy volunteers. These volunteers joined the study following local advertisement. This group comprised 5 women and 5 men with a mean age of $58 \pm 11$ years. Their health status was certified by their family physician as per review of their medical records. The blood samples of all the controls from the healthy group and the stable COPD group were drawn independent of the cohort with COPDE. This study was approved by the Research Ethics Board of Soroka Hospital, Ben-Gurion University and Tel Aviv Sourasky Medical Center. A written informed consent was obtained from all participants prior to blood sample collection.

\section{Enrolled COPDE patients}

CfDNA levels were obtained simultaneously with arterial blood gases, oxygen saturation, chemistry and cell count on presentation of patients to the ED. Patients were assessed during the first 12 hours of admission. The following variables were evaluated: demographics, comorbidities, oxygen requirements and need for noninvasive home ventilation.

\section{Patient follow-up}

Clinical data on mechanical ventilation, ICU admission and mortality were monitored. At discharge, patients with COPDE underwent spirometry and were referred for follow-up 1 month after discharge in the pulmonology clinic. cfDNA levels were repeated for only a small group of patients within 48 hours of admission or at 1 month.

The rationale for choosing these time points to monitor the levels of cfDNA is that COPDEs are characterized by infectious and inflammatory processes. The time points were chosen based on previous studies that have described 48 hours as an acceptable time frame to assess first signs of treatment response and 1 month as an appropriate duration after COPDE to ensure stabilization. ${ }^{28-30}$

\section{cfDNA measurements}

CfDNA levels were detected directly in sera, according to the method designed by us. ${ }^{25}$ Briefly, $10 \mu \mathrm{L}$ of sera or DNA standard solutions were applied in duplicate to black 96-well plates (Greiner Bio-One, Frickenhausen, Germany). About $40 \mu \mathrm{L}$ of diluted $\operatorname{Sybr}^{\circledR}$ Gold was added to each well (final dilution 1:10,000), and fluorescence was measured with a 96-well fluorometer (Spectrafluor Plus; Tecan, Durham, $\mathrm{NC}, \mathrm{USA}$ ) at an emission wavelength of $535 \mathrm{~nm}$ and an 
excitation wavelength of $485 \mathrm{~nm}$. Concentrations of unknown samples were calculated from a standard curve by extrapolation in a linear regression model. As described previously, our assay correlates with the conventional quantitative PCR assay of $\beta$-globin $\left(R^{2}=0.9987, P<0.001\right) .{ }^{17}$

\section{Statistical analysis}

Analysis was performed using Graph-Pad Prism (VS 4.0) and $\mathrm{R}$ (version 3.02). Continuous variables are expressed as mean $\pm \mathrm{SD}$ or median with IQR $(25 \%-75 \%)$. Frequencies and proportions are reported for categorical variables. Parametric model assumptions were assessed using Kolmogorov-Smirnov and Shapiro-Wilks statistic for verification of normality. Comparison was done by Student's $t$-test or Mann-Whitney $U$-test where appropriate. To compare categorical variables, we used independent chi-square tests.

cfDNA levels were divided into tertiles, and associations between tertiles with respect to clinical parameters were determined using analysis of variance with Bonferroni posttest. Pearson's correlation was used to assess the association of cfDNA with clinical and laboratory parameters. A multivariable regression model was utilized to assess the contributions of age, sex, arterial blood gas parameters and need for noninvasive ventilatory support on cfDNA levels. The relationship between abnormal blood gas parameters $\left(\mathrm{PaCO}_{2}>45 \mathrm{mmHg}\right.$ and $\left.\mathrm{pH}<7.36\right)$ and cfDNA at the time of a COPDE was investigated by ROC analysis. Paired $t$-tests were used to assess the change in cfDNA levels at 48 hours and 1 month after a COPDE. Survival was assessed using Kaplan-Meier curves and Cox proportional hazard models. A $P$-value of $<0.05$ was considered statistically significant for all analyses.

\section{Results}

\section{Study population and clinical course}

One hundred and twelve patients from the ED with a clinical diagnosis of COPDE were initially enrolled. Patients with no cfDNA samples and patients with samples taken after initial treatment with corticosteroids, bronchodilators, oxygen or noninvasive ventilation in the ED were excluded from the study in order not to confound cfDNA measurements. We also excluded patients who did not satisfy the criteria for a spirometric diagnosis of COPD (Figure 1).

Sixty-two patients (46 males and 16 females) with a mean age of $65 \pm 10$ years were included in the study. According to GOLD criteria, 15 patients $(24.3 \%)$ were stage IV, 32 patients $(51.6 \%)$ were stage III, 11 patients $(17.7 \%)$ were stage II and none were stage I. The mean $\mathrm{FEV}_{1}$ of the entire

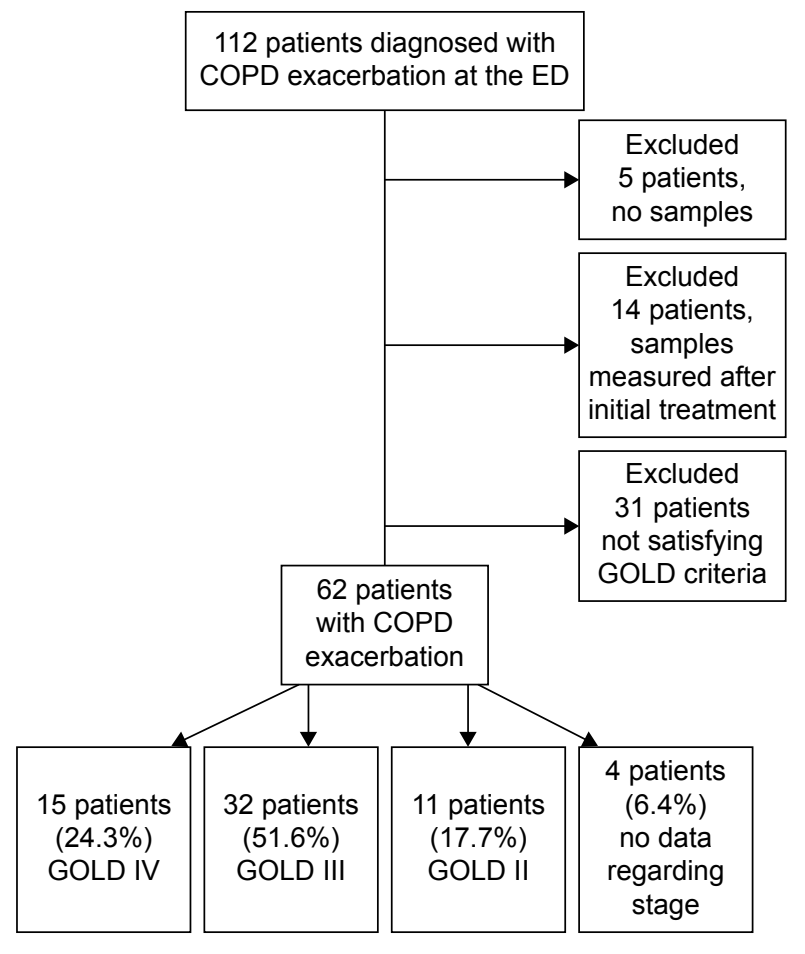

Figure I Flowchart of patients who met inclusion/exclusion criteria for the study population.

Abbreviations: ED, emergency department; GOLD, Global Initiative for Chronic Obstructive Lung Disease.

group was $38 \% \pm 13 \%$. We had no data regarding the GOLD stage of 4 patients, but these patients were documented to be assessed by spirometry and have a spirometric diagnosis of COPD with an $\mathrm{FEV}_{1} / \mathrm{FVC}$ ratio of $<0.70$. The median hospital length of stay was 4 days (IQR [3-6]). There were no deaths reported during the hospital admission, and none of the patients required invasive ventilation or ICU transfer after admission. Eleven patients required noninvasive ventilation with 4 of these patients previously using noninvasive ventilatory support at home.

\section{cfDNA biomarker for COPDE compared to COPD controls in stable state and healthy controls}

Levels of cfDNA at the time of COPDE were elevated compared to those observed in COPD controls under stable condition and healthy controls (Figure 2). The median cfDNA levels for COPDE patients on admission was $1,634 \mathrm{ng} / \mathrm{mL}$ (IQR [1,016-2,319]) compared to $781 \mathrm{ng} / \mathrm{mL}$ (IQR [523-855]) for age and GOLD stage (II-IV) stable COPD patients, and $352 \mathrm{ng} / \mathrm{mL}$ (IQR [209-636]) for healthy controls $(P<0.0001$, both comparisons $)$. The levels of cfDNA were elevated among the stable COPD patients compared to healthy controls ( $P=0.014$, Figure 2$)$. 


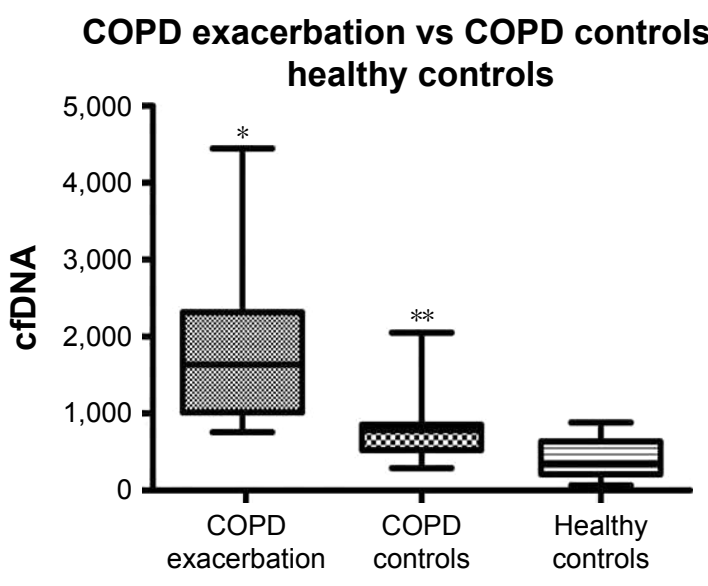

Figure 2 Cell-free DNA (cfDNA) levels of COPD exacerbation group vs COPD stable control and healthy controls.

Notes: COPD exacerbation ( $n=62), 1,634 \mathrm{ng} / \mathrm{mL}($ IQR I,016-2,319) vs COPD controls ( $n=16), 781 \mathrm{ng} / \mathrm{mL}$ (IQR 523-855) vs Healthy controls $(n=10), 352 \mathrm{ng} / \mathrm{mL}$ (IQR 209-636). *COPD exacerbation vs COPD controls and COPD exacerbation vs healthy controls, $P<0.000$ I for both comparisons; ${ }^{* *}$ COPD controls vs Healthy controls, $P=0.014$.

Abbreviation: IQR, interquartile range.

\section{Correlation of cfDNA to clinical and laboratory data during COPDE}

The study group was divided into tertiles based on the cfDNA levels (Table 1). The median levels of cfDNA in the lowest tertile was $972 \mathrm{ng} / \mathrm{mL}$ (IQR [880-1,034]) and the highest tertile was $2,804 \mathrm{ng} / \mathrm{mL}$ (IQR $[2,311-3,636])$, with $P<0.0001$ for all tertiles. There was a significant correlation of cfDNA levels with blood gas parameters at the time of admission: $\mathrm{PaCO}_{2}(r=0.35)$ and $\mathrm{pH}(r=-0.35), P=0.01$ for both comparisons. The mean $\mathrm{PaCO}_{2}$ levels were significantly lower in the lowest tertile $(43 \pm 9 \mathrm{mmHg})$ compared to those of the highest tertile (59 \pm 18$), P=0.008$. Similarly, the mean $\mathrm{pH}$ value of the highest cfDNA tertile was more acidotic than the lower and middle tertiles (Table 1). There were no differences across cfDNA tertiles with respect to the following parameters: age, sex, length of hospital stay, need for noninvasive ventilation or $\mathrm{PaO}_{2}$ as shown in Table 1 . There was a nonsignificant association between cfDNA levels and $\mathrm{FEV}_{1} \%(r=-0.19$, $P=0.15)$ and $\mathrm{FEV}_{1} / \mathrm{FVC}$ ratio $(r=-0.11, P=0.45)$.

$\mathrm{PaCO}_{2}$ was the only independent predictor of cfDNA. For an increase of every $10 \mathrm{mmHg}$ in $\mathrm{PaCO}_{2}$, there was an increase in cfDNA by $225 \mathrm{ng} / \mathrm{mL}$ (95\% CI 53-396) after adjusting for age, sex and requirement for noninvasive ventilation. We generated ROC curves to further determine the association of plasma cfDNA with $\mathrm{PaCO}_{2}$ and $\mathrm{pH}$ from blood gases (Figure 3A and B). The most accurate cut-point for cfDNA in predicting abnormal $\mathrm{PaCO}_{2}$ levels $(>45 \mathrm{mmHg})$ was $1,924 \mathrm{ng} / \mathrm{mL}$. The AUC for $\mathrm{PaCO}_{2}>45 \mathrm{mmHg}$ was 0.68 (95\% CI $0.53-0.82, P=0.02)$ and for $\mathrm{pH}<7.36$ it was 0.7 (95\% CI 0.56-0.84, $P=0.01)$.

\section{cfDNA levels over time}

Repeat cfDNA levels were obtained in 12 patients during admission and at 48 hours in hospital. Seven patients had repeat plasma cfDNA levels 1 month post-hospital discharge. cfDNA levels decreased within 48 hours and 1 month post-discharge, but a significant difference was seen only at 1 month (acute: 2305 [1,686-2,547] vs 1 month: 1,015 [665-1,309], $P=0.0003$; Figure 4A and B).

Table I Cell-free DNA divided into tertiles

\begin{tabular}{|c|c|c|c|c|}
\hline Parameter & $\begin{array}{l}\text { Lowest tertile } \\
(n=21)\end{array}$ & $\begin{array}{l}\text { Intermediate } \\
(n=20)\end{array}$ & $\begin{array}{l}\text { Highest tertile } \\
(n=21)\end{array}$ & $P$-value \\
\hline DNA level (IQR) & $972 \mathrm{ng} / \mathrm{mL}(880-1,034)$ & $\mathrm{I}, 634(\mathrm{I}, 46 \mathrm{I}-\mathrm{I}, 75 \mathrm{I})$ & $2,804(2,3 \mid I-3,636)$ & $<0.000 I^{\mathrm{a}}$ \\
\hline Age, years $( \pm S D)$ & $68 \pm 9$ & $6 I \pm 8$ & $66 \pm 11$ & 0.053 \\
\hline Male sex & $14(67 \%)$ & $15(75 \%)$ & 17 (8I\%) & 0.57 \\
\hline \multicolumn{5}{|l|}{ Pulmonary function tests } \\
\hline $\mathrm{FEV}_{1} / \mathrm{FVC}$ & $56 \pm 8$ & $53 \pm 12$ & $55 \pm 10$ & 0.71 \\
\hline $\mathrm{FEV}_{1}(\%),(\mathrm{n}=58)$ & $39 \pm 10$ & $40 \pm 15$ & $34 \pm 13$ & 0.34 \\
\hline \multicolumn{5}{|l|}{ Blood gases } \\
\hline $\mathrm{pH}$ & $7.38 \pm 0.04$ & $7.37 \pm 0.05$ & $7.33 \pm 0.06$ & $0.009^{b}$ \\
\hline $\mathrm{PaCO}_{2}(\mathrm{mmHg})$ & $43 \pm 9$ & $50 \pm 15$ & $59 \pm 18$ & $0.008^{c}$ \\
\hline $\begin{array}{l}\mathrm{PaO}_{2}(\mathrm{mmHg}) \\
\text { median }(\mathrm{IQR})\end{array}$ & $89(60-93)$ & $86(7 \mid-95)$ & $75(69-84)$ & 0.29 \\
\hline $\begin{array}{l}\text { Hospital length of stay, } \\
\text { median days (IQR) }\end{array}$ & $4(3-7)$ & $4(3-6)$ & $4(3-6)$ & 0.51 \\
\hline $\begin{array}{l}\text { Noninvasive ventilation } \\
\text { during hospital }\end{array}$ & $3(14 \%)$ & $4(20 \%)$ & $4(19 \%)$ & 0.88 \\
\hline
\end{tabular}

Notes: Data presented as median (IQR), mean $\pm \mathrm{SD}$, or $\mathrm{n}(\%)$. ${ }^{\mathrm{a} A l l}$ tertiles $\mathrm{P}<0.05$, post-hoc Bonferroni comparison between tertiles: ${ }^{\mathrm{b}}(\mathrm{lowest}$ and intermediate) vs highest, $P<0.05$; clowest vs highest only, $P<0.05$.

Abbreviations: $\mathrm{FEV}_{1}$, forced expiratory volume in I second; $\mathrm{FVC}$, forced vital capacity; IQR, interquartile range; $\mathrm{PaCO}$, partial arterial pressure of carbon dioxide; $\mathrm{PaO}$, partial arterial pressure of oxygen; SD, standard deviation. 

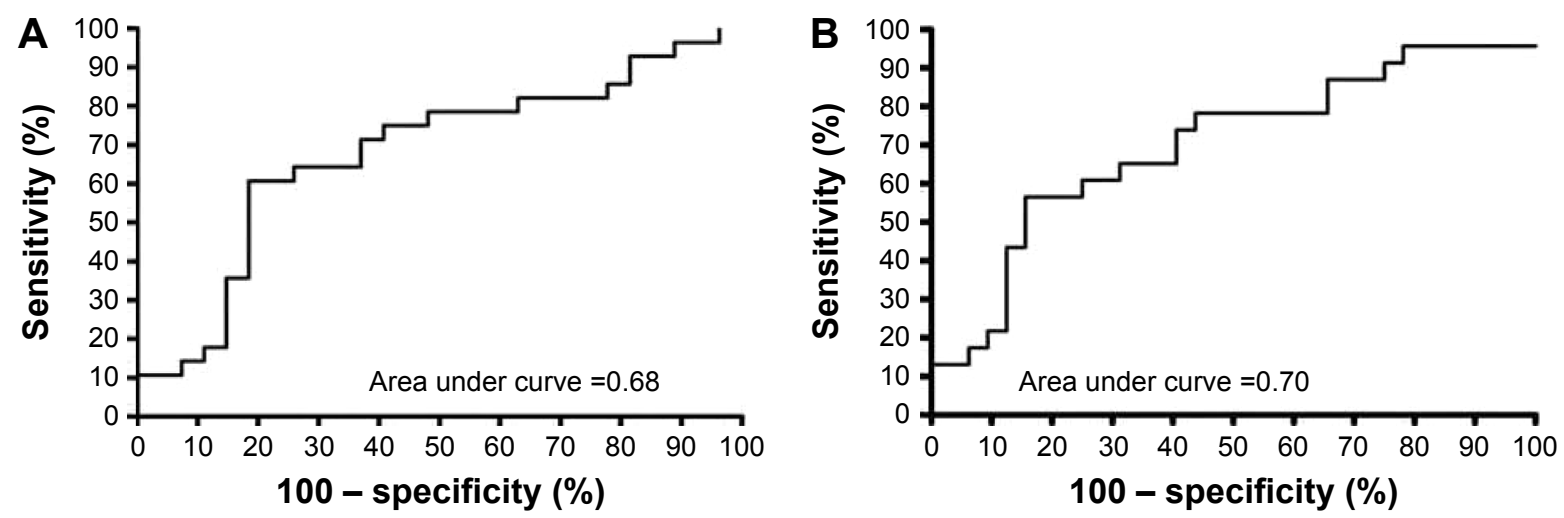

Figure 3 (A) ROC curve for blood gas $\mathrm{PaCO}_{2}$; (B) ROC curve for blood gas $\mathrm{pH}$.

Notes: (A) Area under curve for $\mathrm{PaCO}_{2}>45 \mathrm{mmHg}$ was 0.68 (95\% $\left.\mathrm{Cl} 0.53-0.82, \mathrm{P}=0.02\right)$. (B) Area under curve for $\mathrm{pH}<7.36 \mathrm{was} 0.7(95 \% \mathrm{Cl} 0.56-0.84, \mathrm{P}=0.01)$. Arterial blood gases were drawn simultaneously with the cfDNA levels.

Abbreviations: $\mathrm{PaCO}_{2}$, partial arterial pressure of carbon dioxide; ROC, receiver operating characteristic.

\section{cfDNA levels at the time of COPDE as a predictor of survival}

There was an increased 5-year survival rate in the low-cfDNA group $(<1,924 \mathrm{ng} / \mathrm{mL})$ compared to the high-cfDNA group $(\geq 1,924 \mathrm{ng} / \mathrm{mL}, P=0.035)$ as illustrated in Figure 5. When adjusted for age, sex and $\mathrm{FEV}_{1} \%$, patients with high cfDNA levels at the time of a COPDE had a trend for increased risk of mortality over 5 years (HR 1.92, 95\% CI 0.93-3.95, $P=0.08$ ) (Table 2).

\section{Discussion}

In this study, we observed that cfDNA levels were elevated in patients during a COPDE and were closely associated with arterial blood gas parameters. cfDNA levels were also responsive to changes, as observed with decreasing levels over time. Furthermore, increased cfDNA levels predicted 5 -year survival rate. To our knowledge, this is the first study to assess the clinical implications of cfDNA levels in the setting of an acute COPDE.

COPDE is still challenging for diagnosis and prognostic assessment. The clinical and laboratory markers that are commonly used are not optimal for monitoring. Moreover, laboratory tests might be abnormal at baseline in this group of patients and are not specific for acute events or dynamic changes to monitor progress or improvement in the course of the disease. ${ }^{7,31}$ Few biomarkers such as CRP, procalcitonin, copeptin ${ }^{7,31-33}$ and proadrenomedullin levels ${ }^{34}$ at discharge were tested in COPD patients for evaluating the associations of cfDNA levels with severity and survival, but none of the markers tested at the time of exacerbation showed correlation with long-term survival. ${ }^{7}$

In recent years, we have acquired increasing knowledge about the pathophysiology of COPD. COPD can be thought of as a systemic disease with exacerbations marked by
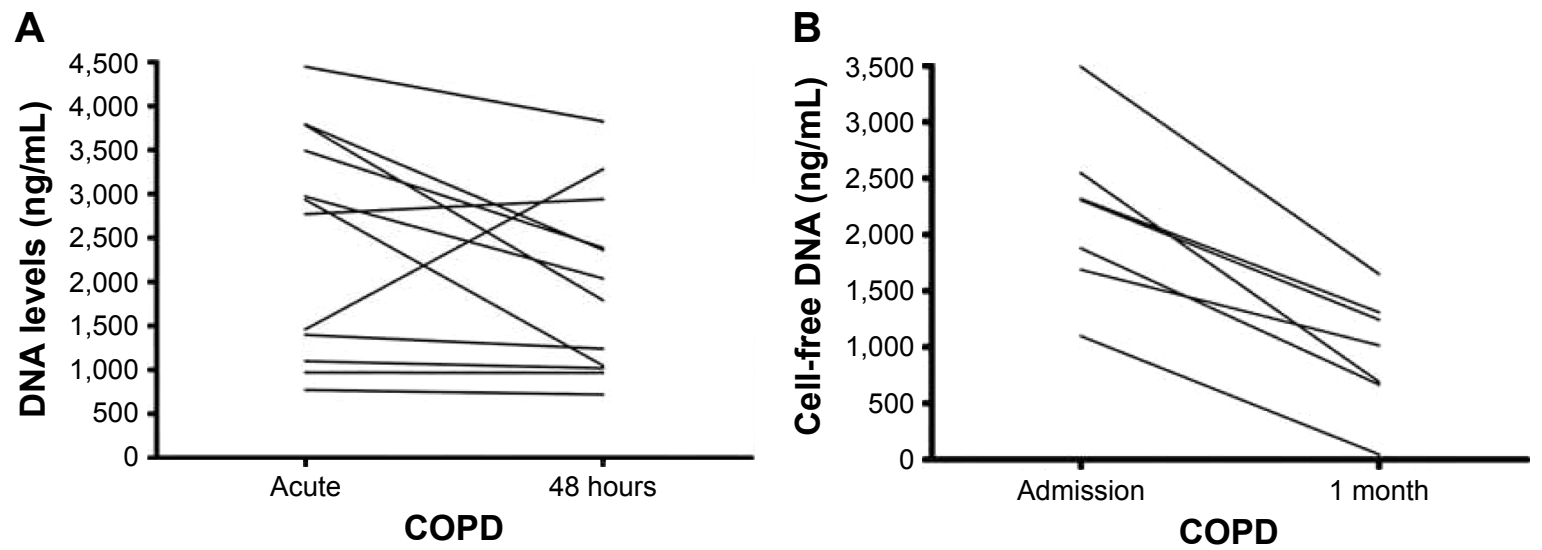

Figure 4 (A) Cell-free DNA levels at admission and 48 hours. (B) Cell-free DNA levels at admission and clinic (I-month post).

Notes: (A) COPD acute DNA levels $(2,853 \mathrm{ng} / \mathrm{mL}$ (IQR I,249-3,636) vs 48 hours (I,918 ng/mL (IQR I,686-2,547), P=0.1। (paired t-test) in I2 patients. (B) COPD acute DNA levels $(2,305 \mathrm{ng} / \mathrm{mL}$ (IQR I,249-3,636) vs I month (I,0I5 ng/mL (IQR 665-I,309), $P=0.0003$ (paired $t$-test) in 7 patients.

Abbreviation: IQR, interquartile range. 


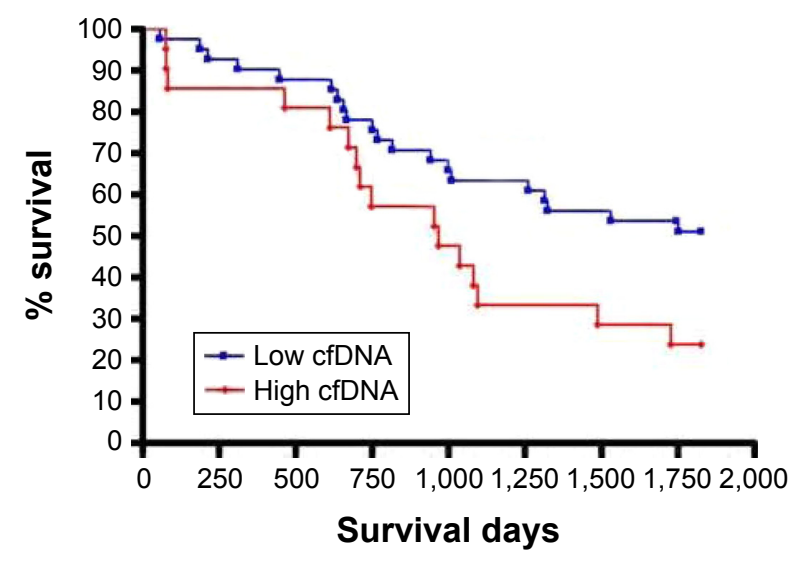

Figure 5 Survival curve based on cfDNA levels.

Note: Low cfDNA $(<1,924 \mathrm{ng} / \mathrm{mL})$ vs normal cfDNA levels ( $\geq 1,924 \mathrm{ng} / \mathrm{mL}), P=0.035$. Abbreviation: cfDNA, cell-free DNA.

inflammation and cellular processes such as apoptosis. ${ }^{10}$ cfDNA is a biomarker that is associated with an inflammatory cascade of cell necrosis, apoptosis and active cell secretion. The source of cfDNA in COPDE has various inflammatory, infectious and thrombotic processes accompanied by destruction of cells and recruitment of inflammatory cells. Moreover, cfDNA is probably not only a biomarker of these processes but also an active factor contributing to immune and inflammatory processes. ${ }^{22,35-38}$ This study excluded patients with sepsis or pneumonia based on clinical, laboratory and radiological assessment. COPDEs are often marked by infectious processes such as pneumonia or concomitant airway infections. Even though it is difficult to isolate the relationship between cfDNA levels and inflammation from a noninfectious etiology, exclusion of patients with sepsis or pneumonia increased the specificity of this marker for assessing COPDE. In our previous work, ${ }^{24}$ no association was observed between cfDNA levels and microorganisms or source of sepsis. In the present study, cfDNA was found to be a good clinical marker during a COPDE as observed in other medical conditions. ${ }^{17,19}$ Previous studies showed the presence of damaged DNA in plasma of patients with COPD, ${ }^{38,39}$ but did not assess its clinical implications.
A new, simple fluorometric method for measuring cfDNA with fast processing times was used in the present study. This is in contrast to previous techniques such as quantitative PCR, the most widely applied technique for assessing cfDNA levels, which is costly and labor-intensive. In addition, quantitative PCR assays measure the number of gene copies under investigation and not the DNA concentration. Thus, quantitative PCR is affected by extraction losses, DNA fragmentation and PCR efficiency. In contrast, measurement of DNA concentration by our assay requires only a small serum or plasma sample, and the collected blood can be kept at room temperature for several hours. Furthermore, no extraction or incubation is required, and the results are promptly available. ${ }^{25}$ In our view, this simple technique allows for rapid and effective evaluation of patients in the ED during a COPDE.

We have shown in this study that levels of plasma cfDNA were higher in COPD patients at the time of exacerbation compared to patients with COPD in stable condition and healthy controls, reflecting the systemic inflammatory response that characterizes COPDE. Interestingly, cfDNA levels were elevated significantly in a small group of stable COPD patients compared to a group of healthy volunteers, potentially suggesting an element of chronic inflammation. Furthermore, in a relatively small group of 12 patients that had sequential measurements of plasma cfDNA levels 48 hours after admission and 7 patients 1 month after discharge from the hospital, we observed that levels of cfDNA declined with routine COPD management and duration post-exacerbation, suggesting a parallel response in cfDNA levels. Decreased levels of cfDNA with clinical and laboratory improvement were also previously observed in other acute processes such as acute myocardial infarction and sepsis. ${ }^{20,22}$

Our goal in the present study was not only to show that cfDNA is a marker for acute exacerbation but also to assess the ability of this marker to predict prognosis. We observed that cfDNA during a COPDE was significantly elevated compared to a control group of stable COPD patients. cfDNA was also associated with other known disease-related

Table 2 Mortality risk of clinical characteristics and cfDNA levels

\begin{tabular}{|c|c|c|c|c|}
\hline Parameter & $\begin{array}{l}\text { Unadjusted HR } \\
(95 \% \mathrm{Cl})\end{array}$ & $P$-value & $\begin{array}{l}\text { Adjusted HR } \\
(95 \% \mathrm{Cl})\end{array}$ & $P$-value \\
\hline cfDNA (high $\geq 1,924 \mathrm{ng} / \mathrm{mL}$ vs low levels) & $2.01(1.04-3.89)$ & 0.035 & $1.92(0.93-3.95)$ & 0.08 \\
\hline Age (every 10 years) & $1.74(1.19-2.47)$ & 0.003 & $2.15(1.37-3.37)$ & 0.0009 \\
\hline Male sex & $1.55(0.74-3.86)$ & 0.21 & $0.79(0.34-2.37)$ & 0.83 \\
\hline $\mathrm{FEV} \%, \mathrm{n}=58$ (every $10 \%$ increase) & $0.69(0.52-0.94)$ & 0.02 & $0.60(0.43-0.86)$ & 0.005 \\
\hline
\end{tabular}

Abbreviations: cfDNA, cell-free DNA; $\mathrm{Cl}$, confidence interval; $\mathrm{FEV}_{\text {, }}$, forced expiratory volume in I second; HR, hazard ratio. 
prognostic markers such as $\mathrm{PaCO}_{2} .{ }^{6} \mathrm{We}$ speculate that systemic damage during an exacerbation, represented by levels of cfDNA, might also capture irreversible damage caused by apoptosis and inflammation that is accelerated during exacerbations, ${ }^{37-40}$ and thus, cfDNA could potentially predict long-term prognosis. Finally, a new concept about the role of cfDNA in chronic disease, that it is not only a marker of cell damage and apoptosis but also potentially a factor provoking inflammatory and thrombotic elements in itself. ${ }^{22,41-43}$ Thus, cfDNA reflects not only the severity of an exacerbation like other acute markers, but has potential implications on morbidity and mortality even after stabilization.

Our study has several limitations. This was a single center study with a relatively small sample size. Thus, future observational multicentered studies could help validate our findings. Since $\mathrm{PaCO}_{2}$ is a prognostic parameter that has been shown to be independently associated with mortality in COPDE, to assess survival, we used a cut-point of $1,924 \mathrm{ng} / \mathrm{mL}$ for cfDNA levels that was found to be the most accurate in predicting abnormal $\mathrm{PaCO}_{2}$ levels, as no discriminatory cut-points have been previously established for cfDNA in COPD. It is possible that an alternative lower threshold might be more informative; however, we based our analysis on the fact that hypercapnea has been shown in a number of large-scale studies ${ }^{4,5}$ to be associated with survival. We also did not measure other biomarkers such as C-reactive protein or procalcitonin.

We chose to compare cfDNA to $\mathrm{PaCO}_{2}$ and $\mathrm{pH}$ levels which were found to be associated with prognosis and COPDE severity in previous studies. ${ }^{4-6}$ In previous studies, other markers such as CRP correlated with disease severity, but had limited prognostic utility. ${ }^{7,15,31-34}$ Nevertheless, examining the association between cfDNA levels and inflammatory markers is a potential area of future investigation. Additionally, cfDNA levels were repeatedly measured in only 16 patients, as part of an exploratory analysis in those who agreed for additional follow-up after the acute exacerbation. Thus, we can only conclude that there appears to be a decrease in cfDNA levels over time, but verification in future studies is required to tease out the contribution of a treatment effect.

\section{Conclusion}

This is the first study to assess the clinical application of measuring cfDNA levels in COPD patients. cfDNA levels proved to be elevated during a COPDE compared to stable COPD patients and had good construct validity given its association with $\mathrm{PaCO}_{2}$ levels, a well-described prognostic marker. The present technique of measuring cfDNA levels might help guide COPD management and inform long-term survival. However, application of cfDNA requires further verification in future prospective studies.

\section{Abbreviations}

AUC, area under curve; CI, confidence interval; COPD, chronic obstructive pulmonary disease; COPDE, chronic obstructive pulmonary disease exacerbation; cfDNA, cell-free DNA; CRP, C-reactive protein; ED, emergency department; $\mathrm{FEV}_{1}$, forced expiratory volume in 1 second; FVC, forced vital capacity; GOLD, Global Initiative for Chronic Obstructive Lung Disease; HR, hazard ratio; ICU, intensive care unit; IQR, interquartile range; PCR, polymerase chain reaction; $\mathrm{PaCO}_{2}$, partial arterial pressure of carbon dioxide; $\mathrm{PaO}_{2}$, partial arterial pressure of oxygen; ROC, receiver operating characteristic; SD, standard deviation.

\section{Acknowledgment}

We would like to thank Mrs. Valeria Frishman for her technical assistance.

\section{Author contributions}

Avital Avriel contributed to conception and design, data collection, analysis and interpretation of data, first draft of the article, and revision of the article critically for important intellectual content. Dmitry Rozenberg contributed to analysis and interpretation of data, and revision of the article critically for important intellectual content. Yael Raviv contributed to interpretation of data and revision of the article critically for important intellectual content. Dov Heimer contributed to data collection, and revision of the article critically for important intellectual content. Bar-Shai Amir contributed to data collection (stable COPD), interpretation of data, and revision of the article critically for important intellectual content. Rachel Gavish contributed to data collection, interpretation of data, and revision of the article critically for important intellectual content. Jony Sheynin contributed to laboratory analysis, interpretation of data, and revision of the article critically for important intellectual content. Amos Douvdevani contributed to conception and design, interpretation of data, and revision of the article critically for important intellectual content. All authors contributed toward data analysis, drafting and critically revising the paper and agree to be accountable for all aspects of the work.

\section{Disclosure}

Amos Douvdevani submitted a US Patent Application No 13/659,439 “Assay for Detecting Circulating Free Nucleic 
Acids.” Dmitry Rozenberg received salary support from the University of Toronto, Clinician Scientist Training program and Vanier Graduate Scholarship. The other authors report no conflicts of interest in this work.

\section{References}

1. Lange P, Marott JL, Vestbo J, et al. Prediction of the clinical course of chronic obstructive pulmonary disease, using the new GOLD classification: a study of the general population. Am J Respir Crit Care Med. 2012;186(10):975-981.

2. Donaldson GC, Wedzicha JA. COPD exacerbations. 1: Epidemiology. Thorax. 2006;61(2):164-168.

3. McGhan R, Radcliff T, Fish R, Sutherland ER, Welsh C, Make B. Predictors of rehospitalization and death after a severe exacerbation of COPD. Chest. 2007;132(6):1748-1755.

4. Groenewegen KH, Schols AM, Wouters EF. Mortality and mortalityrelated factors after hospitalization for acute exacerbation of COPD. Chest. 2003;124(2):459-467.

5. Soler-Cataluna JJ, Martinez-Garcia MA, Roman Sanchez P, Salcedo E, Navarro M, Ochando R. Severe acute exacerbations and mortality in patients with chronic obstructive pulmonary disease. Thorax. 2005;60(11):925-931.

6. Franciosi LG, Page CP, Celli BR, et al. Markers of exacerbation severity in chronic obstructive pulmonary disease. Respir Res. 2006;7:74.

7. Hurst JR, Donaldson GC, Perera WR, et al. Use of plasma biomarkers at exacerbation of chronic obstructive pulmonary disease. Am J Respir Crit Care Med. 2006;174(8):867-874.

8. Warwick G, Thomas PS, Yates DH. Non-invasive biomarkers in exacerbations of obstructive lung disease. Respirology. 2013;18(5): 874-884.

9. Shaw JG, Vaughan A, Dent AG, et al. Biomarkers of progression of chronic obstructive pulmonary disease (COPD). JThorac Dis. 2014; 6(11):1532-1547.

10. Thomsen M, Ingebrigtsen TS, Marott JL, et al. Inflammatory biomarkers and exacerbations in chronic obstructive pulmonary disease. JAMA. 2013;309(22):2353-2361.

11. Schmidt-Ioanas M, Pletz MW, de Roux A, Lode H. Apoptosis of peripheral blood neutrophils in COPD exacerbation does not correlate with serum cytokines. Respir Med. 2006;100(4):639-647.

12. Bhowmik A, Seemungal TA, Sapsford RJ, Wedzicha JA. Relation of sputum inflammatory markers to symptoms and lung function changes in COPD exacerbations. Thorax. 2000;55(2):114-120.

13. Makris D, Vrekoussis T, Izoldi M, et al. Increased apoptosis of neutrophils in induced sputum of COPD patients. Respir Med. 2009;103(8): $1130-1135$.

14. Hodge S, Hodge G, Holmes M, Reynolds PN. Increased airway epithelial and T-cell apoptosis in COPD remains despite smoking cessation. Eur Respir J. 2005;25(3):447-454.

15. Lichtenstern C, Brenner T, Bardenheuer HJ, Weigand MA. Predictors of survival in sepsis: what is the best inflammatory marker to measure? Curr Opin Infect Dis. 2012;25(3):328-336.

16. Zanetti-Dällenbach RA, Schmid S, Wight E, et al. Levels of circulating cell-free serum DNA in benign and malignant breast lesions. Int J Biol Markers. 2007;22(2):95-99.

17. Czeiger D, Shaked G, Eini H, et al. Measurement of circulating cell-free DNA levels by a new simple fluorescent test in patients with primary colorectal cancer. Am J Clin Pathol. 2011;135(2):264-270.

18. Lam NY, Rainer TH, Chan LY, Joynt GM, Lo YM. Time course of early and late changes in plasma DNA in trauma patients. Clin Chem. 2003; 49(8):1286-1291.

19. Chang CP, Chia RH, Wu TL, Tsao KC, Sun CF, Wu JT. Elevated cell-free serum DNA detected in patients with myocardial infarction. Clin Chim Acta. 2003;327(1-2):95-101.

20. Shimony A, Zahger D, Gilutz H, et al. Cell free DNA detected by a novel method in acute ST-elevation myocardial infarction patients. Acute Card Care. 2010;12(3):109-111.
21. Tovbin D, Novack V, Wiessman MP, Abd Elkadir A, Zlotnik M, Douvdevani A. Circulating cell-free DNA in hemodialysis patients predicts mortality. Nephrol Dial Transplant. 2012;27(10):3929-3935.

22. Dwivedi DJ, Toltl LJ, Swystun LL, et al. Prognostic utility and characterization of cell-free DNA in patients with severe sepsis. Crit Care. 2012;16(4):R151.

23. Rhodes A, Wort SJ, Thomas H, Collinson P, Bennett ED. Plasma DNA concentration as a predictor of mortality and sepsis in critically ill patients. Crit Care. 2006;10(2):R60.

24. Avriel A, Paryente Wiessman M, Almog Y, et al. Admission cell free DNA levels predict 28-day mortality in patients with severe sepsis in intensive care. PloS One. 2014;9(6):e100514.

25. Goldshtein H, Hausmann MJ, Douvdevani A. A rapid direct fluorescent assay for cell-free DNA quantification in biological fluids. Ann Clin Biochem. 2009;46(Pt 6):488-494.

26. Rabe KF, Hurd S, Anzueto A, et al; Global Initiative for Chronic Obstructive Lung Disease. Global strategy for the diagnosis, management, and prevention of chronic obstructive pulmonary disease: GOLD executive summary. Am J Respir Crit Care Med. 2007;176(6):532-555.

27. Tanday S. Rethinking COPD diagnosis: imaging and GOLD criteria. Lancet Respir Med. 2015;3(8):605.

28. Lee KY, Chuang HC, Chen TT, et al. Proteoglycan 4 is a diagnostic biomarker for COPD. Int J Chron Obstruct Pulmon Dis. 2015;10: 1999-2007.

29. Wedzicha JA, Donaldson GC. Exacerbations of chronic obstructive pulmonary disease. Respiratory care. 2003;48(12):1204-1213; discussion 1213-1205.

30. Virzi GM, Milan Manani S, Brocca A, et al. Peritoneal cell-free DNA: an innovative method for determining acute cell damage in peritoneal membrane and for monitoring the recovery process after peritonitis. J Nephrol. 2016;29(1):111-118.

31. Kostikas K, Bakakos P, Papiris S, Stolz D, Celli BR. Systemic biomarkers in the evaluation and management of COPD patients: are we getting closer to clinical application? Curr Drug Targets. 2013;14(2):177-191.

32. Stolz D, Christ-Crain M, Morgenthaler NG, et al. Copeptin, C-reactive protein, and procalcitonin as prognostic biomarkers in acute exacerbation of COPD. Chest. 2007;131(4):1058-1067.

33. Zhao YF, Jiang YP, Zhou LF, Wu XL. The value of assessment tests in patients with acute exacerbation of chronic obstructive pulmonary disease. Am J Med Sci. 2014;347(5):393-399.

34. Grolimund E, Kutz A, Marlowe RJ, et al; ProHOSP Study Group. Long-term prognosis in COPD exacerbation: role of biomarkers, clinical variables and exacerbation type. COPD. 2015;12(3):295-305.

35. Zhang Q, Raoof M, Chen Y, et al. Circulating mitochondrial DAMPs cause inflammatory responses to injury. Nature. 2010;464(7285):104-107.

36. Nakahira K, Kyung SY, Rogers AJ, et al. Circulating mitochondrial DNA in patients in the ICU as a marker of mortality: derivation and validation. PLoS Med. 2013;10(12):e1001577.

37. Cui M, Jing R, Fan M, Zhu J, Ju S. The relationship between cellfree circulating DNA and inflammation in acute coronary syndrome. Cardiology. 2013;126(2):124-125.

38. Maluf SW, Mergener M, Dalcanale L, et al. DNA damage in peripheral blood of patients with chronic obstructive pulmonary disease (COPD). Mutat Res. 2007;626(1-2):180-184.

39. da Silva AL, da Rosa HT, Karnopp TE, et al. Evaluation of DNA damage in COPD patients and its correlation with polymorphisms in repair genes. BMC Med Genet. 2013;14:93.

40. Sigdel TK, Sarwal MM. Cell-free DNA as a measure of transplant injury. Clin Transpl. 2012:201-205.

41. Cichota LC, Bochi GV, Tatsch E, et al. Circulating double-stranded DNA in plasma of hemodialysis patients and its association with iron stores. Clin Lab. 2015;61(8):985-990.

42. Gould TJ, Vu TT, Stafford AR, et al. Cell-free DNA modulates clot structure and impairs fibrinolysis in sepsis. Arterioscler Thromb Vasc Biol. 2015;35(12):2544-2553.

43. Grassle S, Huck V, Pappelbaum KI, et al. von Willebrand factor directly interacts with DNA from neutrophil extracellular traps. Arterioscler Thromb Vasc Biol. 2014;34(7):1382-1389. 
International Journal of COPD

\section{Publish your work in this journal}

The International Journal of COPD is an international, peer-reviewed journal of therapeutics and pharmacology focusing on concise rapid reporting of clinical studies and reviews in COPD. Special focus is given to the pathophysiological processes underlying the disease, intervention programs, patient focused education, and self management protocols.

This journal is indexed on PubMed Central, MedLine and CAS. The manuscript management system is completely online and includes a very quick and fair peer-review system, which is all easy to use. Visit http://www.dovepress.com/testimonials.php to read real quotes from published authors 